\title{
Comparison of Environment, Growth, and Management Performance of the Standard Cut Chrysanthemum 'Jinba' in Conventional and Smart Farms
}

\author{
Yong Seung Roh ${ }^{1}$ and Yong Kweon Yoo ${ }^{1,2^{*}}$ \\ ${ }^{1}$ Research proferssor, The Institute of Natural Resource Development, Mokpo National University, Muan 58554, Korea \\ ${ }^{2}$ Professor, Department of Horticultural Science, Mokpo National University, Muan 58554, Korea
}

\section{ABSTRACT}

Background and objective: This study was conducted to compare the cultivation environment, growth of cut flowers, and management performance of conventional farms and smart farms growing the standard cut chrysanthemum, 'Jinba'. Methods: Conventional and smart farms were selected, and facility information, cultivation environment, cut flower growth, and management performance were investigated.

Results: The conventional and smart farms were located in Muan, Jeollanam-do, and conventional farming involved cultivating with soil culture in a plastic greenhouse, while the smart farm was cultivating with hydroponics in a plastic greenhouse. The conventional farm did not have sensors for environmental measurement such as light intensity and temperature and $\mathrm{pH}$ and $\mathrm{EC}$ sensors for fertigation, and all systems, including roof window, side window, thermal screen, and shading curtain, were operated manually. On the other hand, the smart farm was equipped with sensors for measuring the environment and nutrient solution, and was automatically controlled. The day and night mean temperatures, relative humidity, and solar radiation in the facilities of the conventional and the smart farm were managed similarly. But in the floral differentiation stage, the floral differentiation was delayed, as the night temperature of conventional farm was managed as low as $17.7^{\circ} \mathrm{C}$ which was lower than smart farm. Accordingly, the harvest of cut flowers by the conventional farm was delayed to 35 days later than that of the smart farm. Also, soil moisture and EC of the conventional farm were unnecessarily kept higher than those of the smart farm in the early growth stage, and then were maintained relatively low during the period after floral differentiation, when a lot of water and nutrients were required. Therefore, growth of cut flower, cut flower length, number of leaves, flower diameter, and weight were poorer in the conventional farm than in the smart farm. In terms of management performance, yield and sales price were 10\% and 38\% higher for the smart farm than for the conventional farm, respectively. Also, the net income was 2,298 thousand won more for the smart farm than for the conventional farm.

Conclusion: It was suggested that the improved growth of cut flowers and high management performance of the smart farm were due to precise environment management for growth by the automatic control and sensor.

Keywords: Chrysanthemum morifolium, net income, relative humidity, soil EC, soil moisture, solar radiation, temperature

\section{Introduction}

Korean agriculture is struggling with planned crop production, resulting from problems such as the decline and aging of the farming population, the decrease in agricultural incomes due to declines in capital and labor productivity, a decline in agricultural self-sufficiency, the opening of agricultural markets through FTAs, and the intensifying effects of climate change such as abnormal low and high temperatures (Kim and Huh, 2015). As a way to overcome

\footnotetext{
This work was supported by Korea Institute of Planning and Evaluation for Technology in Food, Agriculture, Forestry (IPET) through Advanced Production Technology Development Program, funded by Ministry of Agriculture, Food and Rural Affairs (MAFRA) (318061-03-2-SB010). Received: December 2, 2020, Revised: December 5, 2020, Accepted: December 9, 2020 First author: Yong Seung Roh, noyong2@mokpo.ac.kr, (D) https://orcid.org/0000-0002-6628-0709 *Corresponding author: Yong Kweon Yoo, yooyong@mokpo.ac.kr, (D) https://orcid.org/0000-0001-6884-163X
} 
these difficulties, smart farm technology incorporating information and communications technology (ICT) into agriculture has been proposed. Smart farms employ a more intelligent and efficient form of agriculture that controls and manages environmental factors such as light, temperature, humidity, nutrient solution, and carbon dioxide concentration to enable an optimal environment; this is done by using automation equipment and ICT to measure and diagnose agricultural and livestock products in real time without time and space constraints (Yoon et al., 2017). Applying smart farm technology enables us to expect increases in quality and yield while reducing the input of water, fertilizer, energy, and labor, and to improve agricultural competitiveness by overcoming the limitations of a small farming scale and the decline and aging of the farming population. When the productivity of tomato farmers that utilized smart farm technology was analyzed, it was found that their production increased by $27.9 \%$, quality improved by $4.7 \%$, and employment and labor costs decreased by $15.9 \%$, showing that the introduction effect was great (Lee and Seol, 2019). In Korea, the "Facility Modernization Project" and the "ICT Convergence Spreading Project" in the field of facility horticulture were promoted to expand the spread of smart farms, but as only a total of 1,441 farms have adopted smart farm technology, the supply rate is less than $3 \%$ of all farms, which means that we are at an early stage of smart farm introduction. In particular, there are only 190 smart farms in the domestic floriculture field, accounting for $15.4 \%$ of the smart farms in the field of facility horticulture, of which 7 farms are chrysanthemum growers; only $3.7 \%$ of farms in the floriculture field are smart farms (Kim et al., 2016).

Chrysanthemum morifolium varieties for cut flowers grown in Korea include 'Jinba', 'Iwanohakusen', and 'Baekma'. Among them, 'Jinba' is the most widely cultivated variety of large white flower in Korea. 'Jinba' is cultivated in forcing, normal and retarding culture methods, produced and distributed from summer to the following spring, and is also the main variety exported to Japan from autumn to spring (Yoo et al., 2016; Roh et al., 2017). To produce high-quality cut chrysanthemums, factors in the cultivation environment in the facility such as light, temperature, humidity and cultivation conditions such as nutrients and moisture in the soil must be properly controlled. Smart farms, which have recently been introduced, can achieve improvements in productivity and quality by adjusting the cultivation environment and conditions appropriately for crops using automated facilities. However, most of the cut chrysanthemum farms in Korea carry out fertigation based on soil in plastic greenhouse facilities; and there are many conventional farms that manually open and close the roof and side windows, heat insulation and shading curtains (Roh and Yoo, 2018).

Therefore, this study aims to provide basic data for the spread of smart farms for cut chrysanthemums by comparing and analyzing the cultivation facilities and environment of conventional and smart farms of Chrysanthemum morifolium 'Jinba', the quality of cut flowers, and management performance.

\section{Research Methods}

\section{Selection of conventional and smart farms and analysis of facility information}

Among the farms cultivating cut chrysanthemum 'Jinba', a greenhouse farm in Ilo-eup, Muan-gun, Jeollanam-do, was selected for this study as a conventional farm, and another greenhouse farm in Muan-eup, Muan-gun as a smart farm. The following were investigated for these two farms: cultivation information such as facility type, area, heating method, screen, presence or absence of roof and side windows, cultivation variety, cultivation method, annual cultivation number, precooling treatment, storage method, domestic shipment, and export status, as well as smart farm system information such as number of control channels, environmental sensors, and nutrient solution control devices.

\section{Analysis of cultivation environment in the conventional and smart farms}

To analyze the cultivation environment of conventional and smart farms, cut chrysanthemum 'Jinba' were measured every 30 minutes from planting to harvesting; temper- 
ature and humidity were monitored with built-in sensors of WatchDog 1650 Micro Station Data Logger (Spectrum Technologies Inc., USA); insolation was measured with a LightScout $^{\circledR}$ Silicon Pyranometer sensor; and soil moisture and EC with a WaterScout ${ }^{\circledR}$ SMEC 300 sensor.

\section{Cut flower cultivation method and growth survey in the conventional and smart farms}

180 rooted cuttings ( $7 \mathrm{~cm}$ long, 5 leaves) of 'Jinba' were planted per $3.3 \mathrm{~m}^{2}$ on October 15 in the conventional farm, and 150 rooted cuttings per $3.3 \mathrm{~m}^{2}$ on October 10 in the smart farm. After planting, cultivation methods such as night lighting, short-day treatment, re-lighting, and daminozide treatment were examined. During flowering, cut flowers were harvested in 3 repetitions at 100 plants per repetition, and then length of cut flower, number of leaves, stem diameter, length of flower neck, flower diameter, fresh weight, and number of days it took to harvest were measured.

\section{Simplified management performance analysis of the conventional and smart farms}

The management performance of conventional and smart farms was analyzed by referring to the simplified management performance analysis method used by the Rural Development Administration (RDA, 2015). The survey was conducted in the form of an interview with a representative of the farms, and the survey items included facility investment (cultivation and smart automation facility installation costs); production and sale price; seeds, fertilizer and pesticide cost; fuel and electricity cost for lighting and heating, and material cost; repair and maintenance cost; employment and family labor cost. Net income was also calculated.

\section{Statistics processing}

On the collected data, an independent sample t-test was performed using the SPSS 25.0 (IBM Inc., USA) to analyze statistical significance.

\section{Results and Discussion}

\section{Analysis of facility information of the conventional and smart farms}

The conventional farm selected in this study was heated with a hot air blower in a $1,157 \mathrm{~m}^{2}$ plastic greenhouse installed in 2004, with two-layer thermal curtains and one-layer shading curtains. Facilities such as ventilation fans, dehumidifiers, electric control facilities, and storage were installed (Table 1). Chrysanthemum morifolium 'Jinba' were mostly planted at 180 plants per $3.3 \mathrm{~m}^{2}$ and cultivated in soil. The cut chrysanthemum cultivar was cultivated as a crop in one year. After harvesting the flowers, they were not pre-cooled, and were stored at $4{ }^{\circ} \mathrm{C}$ and shipped mainly to aT Flowering Plant Joint Mart in Seoul. The skylight and side windows as well as the thermal screen and the shading curtains were controlled manually, and there were no sensors for environmental measurement and $\mathrm{pH}$ and $\mathrm{EC}$ sensors for fertigation.

The smart farm was a $3,300 \mathrm{~m}^{2}$ plastic greenhouse installed in 2008 that was heated with a warm air circulator, and it had two-layer thermal screens and two-layer shading curtains. The difference in facilities from conventional farms was that the smart farm was equipped with a nutrient solution cultivation system and pest control device. Chrysanthemum morifolium 'Baekma' and 'Jinba' were generally planted at 150 plants per $3.3 \mathrm{~m}^{2}$ and cultivated in nutrient solutions. The cut chrysanthemums were cultivated as 2.5 crops in one year, pre-cooled through a low temperature treatment, and stored at $3{ }^{\circ} \mathrm{C}$. Most of the cut flowers that were harvested were shipped to aT Flowering Plant Joint Mart in Seoul, and some cut flowers were exported to Japan. The smart farm had one or two channels for controlling the opening and closing of roof and side windows, and shade curtains and thermal screens, and was equipped with automatically controlled sensors to measure solar radiation, temperature, humidity, $\mathrm{CO}_{2}$, wind speed, rainfall, nutrient solution $\mathrm{pH}$ and $\mathrm{EC}$, which were managed in real time using computers and mobile phone applications.

Unlike in the Netherlands, in Korea, more than $90 \%$ of farms use plastic greenhouses, and thus the application, expansion and dissemination of ICT convergence technology 
is difficult because of the low durability and productivity of these compared to glass greenhouses (Yeo et al., 2016). However, since the smart farm in this study was cultivating using ICT as a PE film greenhouse, it was found that it was possible to implement a smart farm in a plastic greenhouse. Even smart farms employing a plastic greenhouse that grow cut roses were equipped with a system that could automatically control environmental factors such as light quantity and temperature (Choi et al., 2019). Accordingly, given the characteristics of the domestic facility horticulture industry, which is mainly plastic greenhouses, the government is developing a Korean smart greenhouse model that can improve productivity and quality by installing automated facilities in large greenhouses (Yoon et al., 2017).

Table 1. Facility and culture information in conventional and smart farm of Chrysanthemum morifolium 'Jinba'

\begin{tabular}{|c|c|c|c|}
\hline & Category & Conventional farm & Smart farm \\
\hline \multirow{9}{*}{$\begin{array}{c}\text { Facility } \\
\text { information }\end{array}$} & Facility type & PE film greenhouse & PE film greenhouse \\
\hline & Area & $1,157 \mathrm{~m}^{2}$ & $3,300 \mathrm{~m}^{2}$ \\
\hline & Heating system & Kerosene fan heater & Kerosene fan heater \\
\hline & Cooling system & $X$ & $X$ \\
\hline & Thermal screen & Two layer & Two layer \\
\hline & Shading curtain & One layer & Two layer \\
\hline & Roof window openness & Yes & Yes \\
\hline & Side window openness & Yes & Yes \\
\hline & Other facilities & $\begin{array}{l}\text { Ventilating fan, dehumidifier, } \\
\text { supplemental lighting system, } \\
\text { cold storage room }\end{array}$ & $\begin{array}{l}\text { Hydroponic system, sprayer for } \\
\text { pesticide control, ventilating fan, } \\
\text { dehumidifier, supplemental lighting } \\
\text { system, cold storage room }\end{array}$ \\
\hline \multirow{8}{*}{$\begin{array}{c}\text { Culture } \\
\text { information }\end{array}$} & Cultivars & 'Jinba' & 'Baekma', 'Jinba' \\
\hline & Planting density & $180 / 3.3 \mathrm{~m}^{2}$ & $150 / 3.3 \mathrm{~m}^{2}$ \\
\hline & Cultivation system & Soil culture & Hydroponic culture \\
\hline & Number of cropping & 1.0 & 2.5 \\
\hline & Precooling system & $\mathrm{X}$ & Low temperature treatment \\
\hline & Storage method & Dry storage at $4^{\circ} \mathrm{C}$ & Dry storage at $3^{\circ} \mathrm{C}$ \\
\hline & Domestic distribution & Flower auction (Seoul) & Flower auction (Seoul) \\
\hline & Exportation & None & Export to Japan \\
\hline \multirow{13}{*}{$\begin{array}{l}\text { Smart farm } \\
\text { system } \\
\text { information }\end{array}$} & Roof window control & None & 1 channel \\
\hline & Side window control & None & 1 channel \\
\hline & Thermal screen control & None & 2 channel \\
\hline & Shading curtain control & None & 1 channel \\
\hline & Light intensity sensor & None & Yes \\
\hline & Temperature sensor & None & Yes \\
\hline & Humidity sensor & None & Yes \\
\hline & $\mathrm{CO}_{2}$ sensor & None & Yes \\
\hline & Wind speed sensor & None & Yes \\
\hline & Rainfall sensor & None & Yes \\
\hline & Nutrition solution $\mathrm{pH}$ sensor & None & Yes \\
\hline & Nutrition solution EC sensor & None & Yes \\
\hline & Hydroponic control method & $\mathrm{X}$ & Automatic \\
\hline
\end{tabular}




\section{Comparison of cultivation methods of the conventional and smart farms}

Comparing the cultivation method of chrysanthemum morifolium 'Jinba' in the conventional farm and the smart farm, the conventional farm planted 180 rooted cuttings per $3.3 \mathrm{~m}^{2}$ on October 15 , while the smart farm planted 150 per $3.3 \mathrm{~m}^{2}$ on October 10 , and thus the planting was denser in the conventional farm. To suppress floral differentiation through retarding cultivation for both farms, lighting treatment was applied for 4 hours at night in the conventional farm, and for 5 hours 30 minutes in the smart farm, after planting (Table 2). After that, to induce floral differentiation, the conventional farm started a short-day treatment on December 15, resulting in a vegetative growth period of 61 days; while the smart farm did this on November 17 , resulting in a vegetative growth period of 38 days, which was 23 days longer than the conventional farm. In general, the vegetative growth period of chrysanthemum morifolium 'Jinba' in retarding cultivation is about 34 to 52 days (Roh and Yoo, 2010; Choi et al., 2012), and thus it seems that the period of the conventional farm was too long.

Open center occurring in autumn chrysanthemum or dendranthema grandiflorum can be suppressed by reducing ray flowers through relighting treatment for 5-6 days after 12-15 days of short-day treatment (Yoo et al., 2009; Pak et al., 2018), but in this study, the conventional farm applied relighting treatment for 4 hours at night for 5 days from the $8^{\text {th }}$ day of short-day treatment, and the smart farm for 4 hours at night for 5 days on the $15^{\text {th }}$ day of short-day treatment. The cultivar generally reaches the floret formation stage from the involucre-formation stage 12 to 15 days after short-day treatment, but the conventional farm was expected to reduce the number of ray flowers by applying relighting treatment on the $8^{\text {th }}$ day after short-day treatment which did not reach involucre-formation stage. For the purpose of suppressing the peduncle elongation of 'Jinba', daminozide treatment was applied twice with 1000- to 2000-fold dilution in the conventional farm, and twice with 800- to 1000-fold dilution in the smart farm. In the case of Chrysanthemum morifolium 'Baekma', it was found to be effective when daminozide treatment is applied twice with 1000-fold dilution after short-day treatment (Yoo and Roh, 2011), but the conventional farm in this study applied a slightly higher concentration of daminozide than the smart farm.

Cut flowers were harvested on February 12 at the conventional farm, and on January 13 at the smart farm, showing the harvest of the conventional farm was delayed for another 25 days.

\section{Analysis of cultivation environment in the conventional and smart farms}

During the cultivation period of chrysanthemum morifolium 'Jinba', average daytime and nighttime temperatures in the facilities of the conventional and smart farms is shown in Fig. 1. The average daytime temperatures of the conventional and smart farms were $19.0{ }^{\circ} \mathrm{C}$ and $20.2{ }^{\circ} \mathrm{C}$, respectively, and the ranges of daily average temperatures were $12.5-25.6{ }^{\circ} \mathrm{C}$ and $11.7-24.7{ }^{\circ} \mathrm{C}$, respectively (Table 3). As such, there was little difference between the conventional farm and the smart farm in terms of the average daytime and nighttime temperatures. However, the nighttime temperature of the floral differentiation stage for 20 days after short-day treatment was $17.7{ }^{\circ} \mathrm{C}$ for the conventional farm and $22.2{ }^{\circ} \mathrm{C}$ for the smart farm. The appropriate temperature for floral differentiation of 'Jinba' is $20 \sim 23{ }^{\circ} \mathrm{C}$ at night; the lower the temperature is, the slower the floral differentiation proceeds (Kim et al., 2000). As such, it is

Table 2. Cultural method of conventional and smart farm in Chrysanthemum morifolium 'Jinba'

\begin{tabular}{|c|c|c|c|c|c|c|c|c|c|}
\hline \multirow[b]{2}{*}{ Farm } & \multicolumn{2}{|c|}{ Planting method } & \multirow{2}{*}{$\begin{array}{l}\text { Lighting } \\
\text { time }\end{array}$} & \multirow{2}{*}{$\begin{array}{c}\text { Date of } \\
\text { short-day } \\
\text { treatment }\end{array}$} & \multicolumn{2}{|c|}{ Relighting } & \multicolumn{2}{|c|}{ Daminozide treatment } & \multirow{2}{*}{$\begin{array}{c}\text { Harvesting } \\
\text { date }\end{array}$} \\
\hline & $\begin{array}{c}\text { Planting } \\
\text { date }\end{array}$ & $\begin{array}{l}\text { Plating } \\
\text { density }\end{array}$ & & & Date & $\begin{array}{c}\text { Times and } \\
\text { period }\end{array}$ & $\begin{array}{l}\text { Concentration } \\
\left(\mathrm{mg} \cdot \mathrm{L}^{-1}\right)\end{array}$ & Times & \\
\hline $\begin{array}{c}\text { Conventional } \\
\text { farm }\end{array}$ & $\begin{array}{c}15 \\
\text { October }\end{array}$ & $\begin{array}{l}180 \text { plants } \\
\text { per } 3.3 \mathrm{~m}^{2}\end{array}$ & $\begin{array}{c}22: 00 \sim \\
02: 00\end{array}$ & $\begin{array}{c}15 \\
\text { December }\end{array}$ & $\begin{array}{c}23 \\
\text { December }\end{array}$ & $\begin{array}{c}4 \text { hrs for } 5 \\
\text { days }\end{array}$ & $400 \sim 800$ & 2 & $\begin{array}{c}12 \\
\text { February }\end{array}$ \\
\hline Smart farm & $\begin{array}{c}10 \\
\text { October }\end{array}$ & $\begin{array}{l}150 \text { plants } \\
\text { per } 3.3 \mathrm{~m}^{2}\end{array}$ & $\begin{array}{c}21: 00 \sim \\
02: 30\end{array}$ & $\begin{array}{c}17 \\
\text { November }\end{array}$ & $\begin{array}{c}2 \\
\text { December }\end{array}$ & $\begin{array}{c}4 \text { hrs for } 5 \\
\text { days }\end{array}$ & $800 \sim 1000$ & 2 & $\begin{array}{c}13 \\
\text { January }\end{array}$ \\
\hline
\end{tabular}


Table 3. Temperature, relative humidity, and solar radiation, of greenhouse in conventional and smart farm of Chrysanthemum morifolium 'Jinba'

\begin{tabular}{|c|c|c|c|c|c|c|c|c|c|c|}
\hline \multirow{3}{*}{ Farm } & \multicolumn{4}{|c|}{$\begin{array}{c}\text { Temperature } \\
\left({ }^{\circ} \mathrm{C}\right)\end{array}$} & \multicolumn{4}{|c|}{$\begin{array}{l}\text { Relative humidity } \\
\qquad(\%)\end{array}$} & \multicolumn{2}{|c|}{$\begin{array}{l}\text { Solar radiation } \\
\left(\mathrm{W} \cdot \mathrm{m}^{2}\right)\end{array}$} \\
\hline & \multicolumn{2}{|c|}{ Day } & \multicolumn{2}{|c|}{ Night } & \multicolumn{2}{|c|}{ Day } & \multicolumn{2}{|c|}{ Night } & \multirow{2}{*}{ Range } & \multirow{2}{*}{ Mean } \\
\hline & Range & Mean & Range & Mean & Range & Mean & Range & Mean & & \\
\hline Conventional farm & $12.9 \sim 27.2$ & 19.0 & $12.5 \sim 25.6$ & 18.0 & $52.0 \sim 89.2$ & 68.9 & $73.0 \sim 89.6$ & 80.4 & $233 \sim 4805$ & 2399 \\
\hline Smart farm & $9.6 \sim 28.0$ & 20.2 & $11.7 \sim 24.7$ & 17.8 & $54.9 \sim 95.3$ & 71.1 & $71.9 \sim 95.5$ & 84.1 & $211 \sim 4013$ & 2112 \\
\hline
\end{tabular}
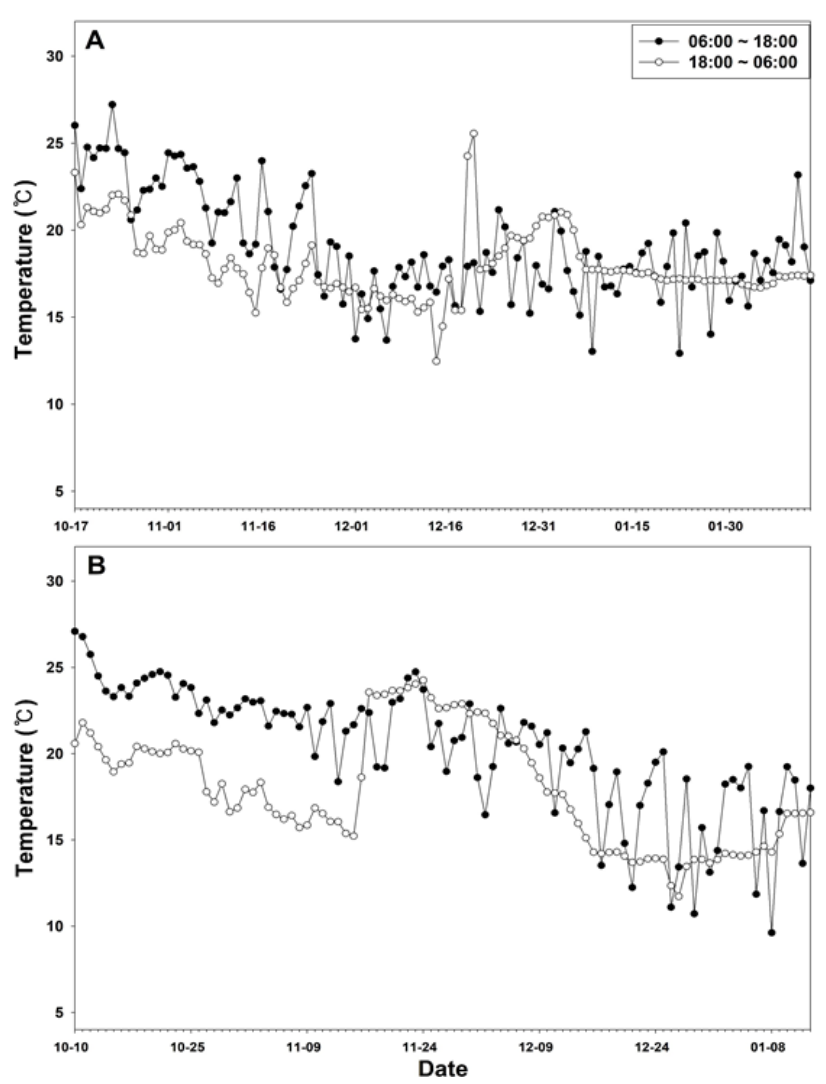

Fig. 1. Comparison of temperature during cultivation period in greenhouse of conventional $(A)$ and smart farm (B) of Chrysanthemum morifolium 'Jinba'.

analyzed that the floral differentiation in the conventional farm was delayed as the temperature was managed lower than the temperature suitable for floral differentiation, and accordingly, the harvest was delayed by 25 days compared to the smart farm. The average relative humidity in daytime and nighttime in the facilities of the conventional and smart farms during the cultivation period of 'Jinba' is shown in Fig. 2. Relative humidity was managed similarly in the facilities of the conventional and smart farms, at daily averages of $68.9 \%$ and $71.1 \%$ and nightly averages of $80.4 \%$
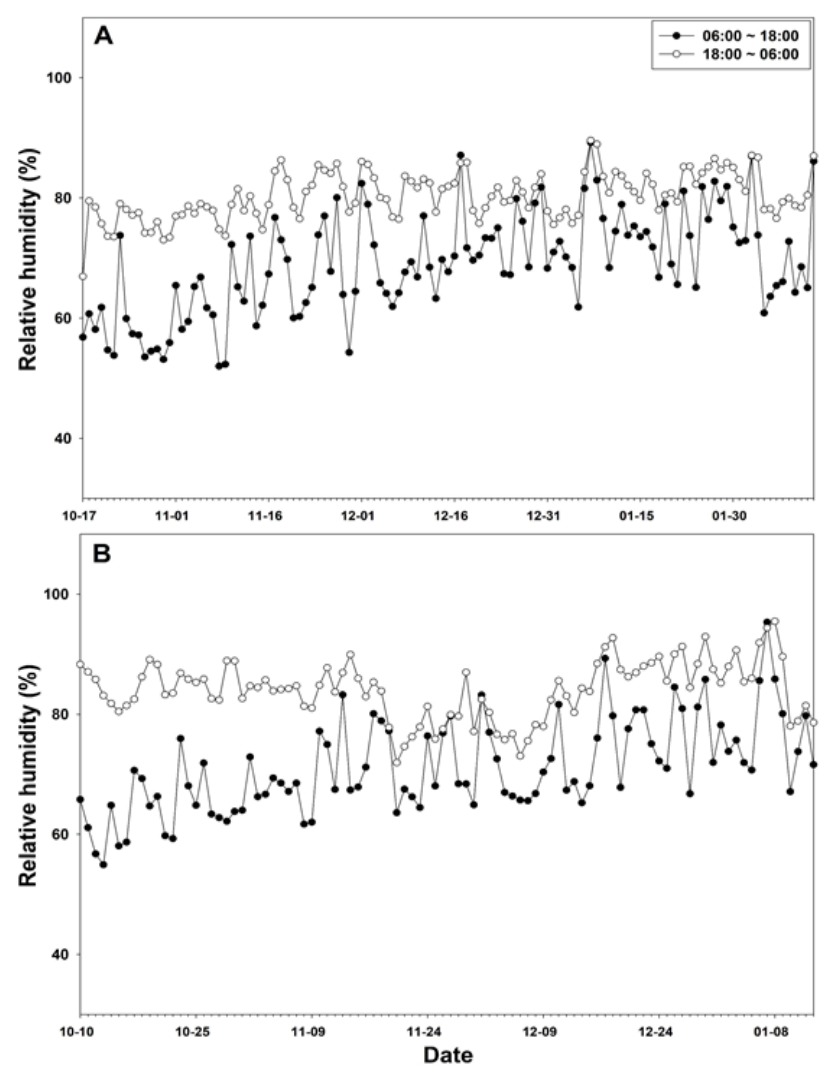

Fig. 2. Comparison of relative humidity during cultivation period in greenhouse of conventional (A) and smart farm (B) of Chrysanthemum morifolium 'Jinba'.

and $84.1 \%$, respectively (Table 3 ). Solar radiation was not significantly different between conventional and smart farms, with an average of 2,399 and $2,112 \mathrm{~W} \cdot \mathrm{m}^{2}$, respectively (Fig. 3, Table 3).

The changes in the average soil moisture of the day and night in the facilities of the farms during the cultivation period of 'Jinba' are shown in Fig. 4. The average daily soil moisture of day and night in the conventional farm was $34.1 \%$ and $34.0 \%$, respectively, and was generally managed to be excessively humid (Fig. 4A, Table 4). In 
Table 4. Soil moisture and EC of greenhouse in conventional and smart farm in Chrysanthemum morifolium 'Jinba'

\begin{tabular}{ccccccc}
\hline \multirow{2}{*}{ Farm } & \multicolumn{2}{c}{ Soil moisture $(\% \mathrm{VMC})$} & & \multicolumn{2}{c}{ Soil EC $\left(\mathrm{dS} \cdot \mathrm{m}^{-1}\right)$} \\
\cline { 2 - 3 } & Day mean & Night mean & & Day mean & 0.8 \\
Conventional farm & 34.1 & 34.0 & 23.7 & & 1.1 & 1.1 \\
Smart farm & 26.5 & & & & 0.8 \\
\hline
\end{tabular}
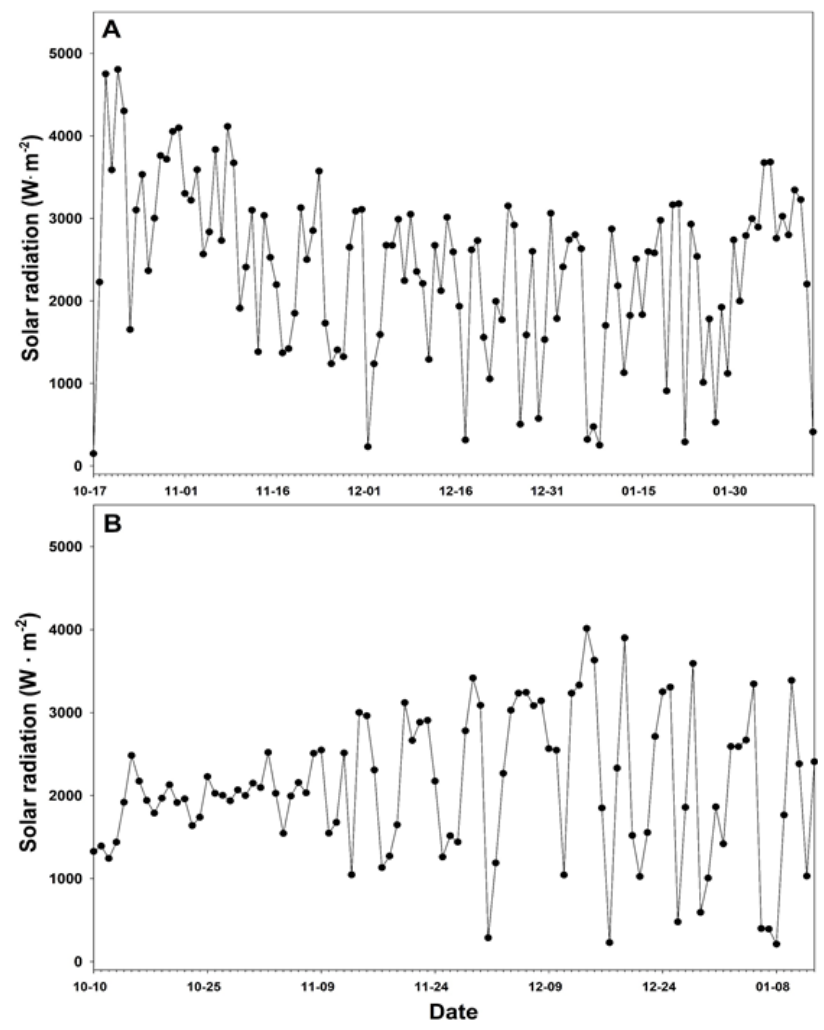

Fig. 3. Comparison of solar radiation during cultivation period in greenhouse of conventional $(A)$ and smart farm (B) of Chrysanthemum morifolium 'Jinba'.

particular, the soil moisture was managed manually according to the empirical judgment of the grower, so it was over-humidified at $40-43 \%$ at the beginning of growth, and the soil moisture was low at $19-28 \%$ after one month of planting, and then was maintained at $30-41 \%$. In the smart farm, soil moisture was managed at $21-27 \%$ during the day and $19-23 \%$ at night until December 12, when floral differentiation was almost complete, and after that, the soil moisture was managed by slowly increasing it to $35 \%$ during the day and $30 \%$ at night (Fig. 4B). For Chrysanthemum morifolium 'Shuhonochikara', it is appropriate to water once every two days before short-day treatment, but after short-day treatment, it was effective for growth when the
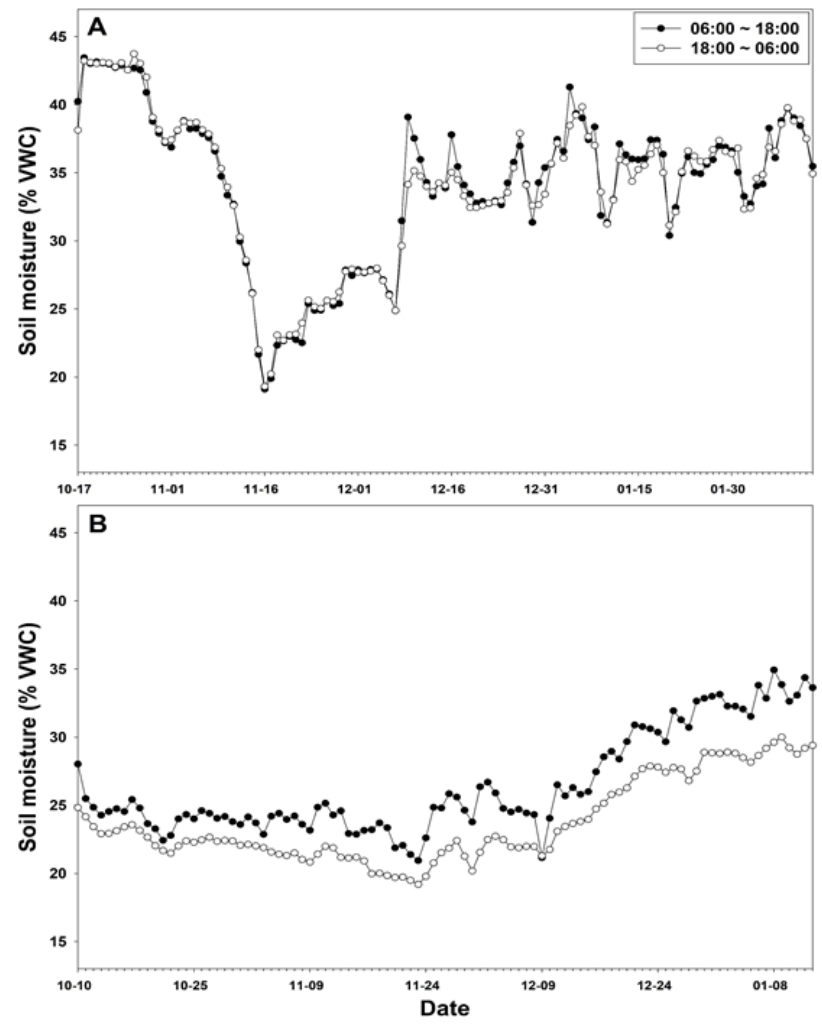

Fig. 4. Comparison of soil moisture during cultivation period in greenhouse of conventional farm (A) and smart farm (B) of Chrysanthemum morifolium 'Jinba'.

soil moisture content was high due to irrigation once or twice a day (Yoo and Kim, 2004). It was thought that the reason why the soil moisture content should be increased after floral differentiation is that a lot of moisture is required for the development of flowers and leaves at this time.

During the cultivation period of chrysanthemum morifolium 'Jinba', the EC levels of soil showed a similar trend to the soil moisture content in both the conventional and the smart farm, which seems to be due to an increase in soil moisture and EC, as the amount of fertigation increased. Soil EC was maintained at $1.8 \mathrm{dS} \cdot \mathrm{m}^{-1}$ after planting, then decreased to $0.3 \mathrm{dS} \cdot \mathrm{m}^{-1}$ for one month, and then increased to $1.4 \mathrm{dS} \cdot \mathrm{m}^{-1}$ two months after planting, and continued 
to decrease thereafter (Fig. 5A). The average soil EC in day and night during the cultivation period was $0.8 \mathrm{dS} \cdot \mathrm{m}^{-1}$ (Table 4). The smart farm controlled the frequency and amount of nutrient solution supplied according to the season and weather, and cultivated cut flowers in a nutrient solution of EC 1.4-1.7 $\mathrm{dS} \cdot \mathrm{m}^{-1}$ using a pearlite medium. Soil EC was managed in the range of 0.8 to $1.3 \mathrm{dS} \cdot \mathrm{m}^{-1}$ before floral differentiation, and then was increased to 1.6 $\mathrm{dS} \cdot \mathrm{m}^{-1}$ until harvest (Fig. 5B). The average soil EC of the day and night during the cultivation period was 1.1 $\mathrm{dS} \cdot \mathrm{m}^{-1}$. Cut chrysanthemum Bongwhang was found to
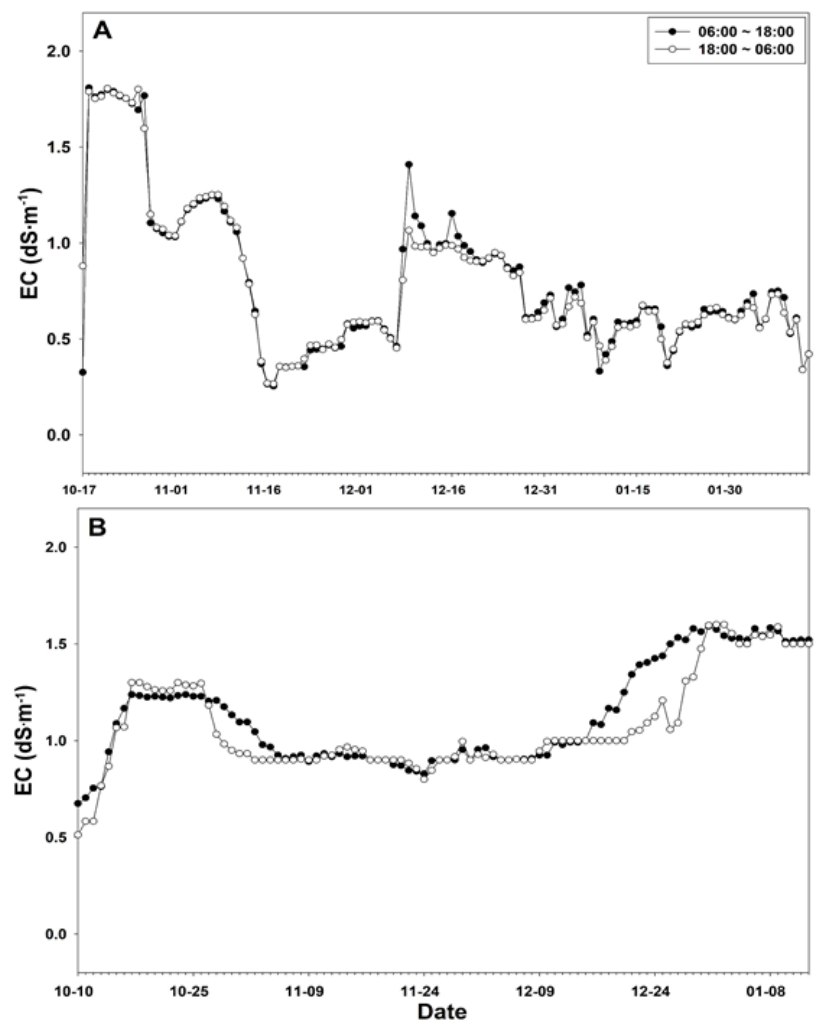

Fig. 5. Comparison of soil EC during cultivation period in greenhouse of conventional (A) and smart farm (B) of Chrysanthemum morifolium 'Jinba'. have the best growth and photosynthesis in the range of EC 1.5 to $2.2 \mathrm{dS} \cdot \mathrm{m}^{-1}$ when grown in nutrient solutions (Hahn et al., 2000), and in the case of 'Jinba', the weight of cut flowers and the growth of flowers were best when cultivated by fertigation under the EC $1.2 \mathrm{dS} \cdot \mathrm{m}^{-1}$ condition (Roh, 2013). Therefore, the smart farm maintained a soil EC concentration that was suitable for the growth of 'Jinba', but the growth in the conventional farm managing the EC concentration to be relatively low was expected be poor due to a lack of nutrients.

\section{Comparison of the growth of cut flowers in the conventional and smart farm}

The growth of 'Jinba' grown and harvested by the conventional and the smart farm was investigated; the length of cut flower was longer in the smart farm $(103.1 \mathrm{~cm})$ than in the conventional farm $(87.7 \mathrm{~cm})$; and the number of leaves was 4.2 more in the smart farm (Table 5). Flower diameter was longer in the smart farm $(11.1 \mathrm{~cm})$ than in the conventional farm $(9.4 \mathrm{~cm})$, and the fresh weight was $30.2 \mathrm{~g}$ heavier in the smart farm than in the conventional farm. In addition, the number of days from planting to harvesting was 120 days for the conventional farm and 95 days for the smart farm, meaning 35 more days was required for the conventional farm. This phenomenon was caused by the smart farm increasing the nighttime temperature during floral differentiation to $20-23{ }^{\circ} \mathrm{C}$, which was higher than in the conventional farm; inducing floral differentiation at the same time; and shortening the cultivation period. Since the smart farm also managed soil moisture and EC to be suitable for the growth of 'Jinba', it could produce high-quality cut flowers.

Table 5. Growth of cut flower cultured in conventional and smart farm in Chrysanthemum morifolium 'Jinba'

\begin{tabular}{cccccccc}
\hline Farm & $\begin{array}{c}\text { Length of cut } \\
\text { flower } \\
(\mathrm{cm})\end{array}$ & $\begin{array}{c}\text { Number of } \\
\text { leaves } \\
(\mathrm{ea})\end{array}$ & $\begin{array}{c}\text { Stem } \\
\text { diameter } \\
(\mathrm{mm})\end{array}$ & $\begin{array}{c}\text { Length of } \\
\text { flower neck } \\
(\mathrm{cm})\end{array}$ & $\begin{array}{c}\text { Flower } \\
\text { diameter } \\
(\mathrm{cm})\end{array}$ & $\begin{array}{c}\text { Fresh } \\
\text { weight } \\
(\mathrm{g})\end{array}$ & $\begin{array}{c}\text { Days to } \\
\text { harvesting }\end{array}$ \\
\hline Conventional farm & 87.7 & 48.3 & 6.3 & 2.1 & 9.4 & 65.4 & 120 \\
\hline Smart farm & 103.1 & 52.5 & 6.7 & 2.4 & 11.1 & 95.6 & \\
\hline Significance & $* *$ & $*$ & $\mathrm{~ns}$ & $\mathrm{~ns}$ & $*$ & $* *$ \\
\hline
\end{tabular}

${ }^{\text {ns Non-significant, }}{ }^{*} p<.05,{ }^{* *} p<.01$. 


\section{Analysis of management performance of the conventional and smart farms}

The total cost spent by the conventional farm in the process of cultivating Chrysanthemum morifolium 'Jinba' was found to be 8,093 thousand won based on $1,000 \mathrm{~m}^{2}$ of plastic greenhouses; the purchase cost of seedlings, fertilizers, pesticides, fuel and electricity for lighting and heating, and other materials was 1,414 thousand won, 317 thousand won, 423 thousand won, 3,010 thousand won, and 242 thousand won, respectively; and employment and family labor cost 2,687 thousand won (Table 6). The total amount of production was 35,360 cut flowers, shipped to the domestic market, and sold at 327 won per flower, resulting in a total income of 11,563 thousand won and a net profit of 3,470 thousand won.

The smart farm installed smart automation facilities in 2008, and the total investment cost was 9,458 thousand won during the cultivation process considering 10-year depreciation on a $1,000 \mathrm{~m}^{2}$ basis. This included automatic facility installation cost of 0 won, seedling cost of 1,350 thousand won, fertilizer cost of 500 thousand won, pesticide cost of 520 thousand won, fuel and electricity cost of 3,000 thousand won for lighting and heating, material cost of 238 thousand won, and employment and family labor cost of 3,850 thousand won. It was analyzed that the reason why the fertilizer purchase cost was higher than that of the conventional farm was due to the fact that a nutrient solution was supplied every day until the day of harvest, and the reason for the high labor cost was that a number of daily workers were employed; family labor cost was 500 thousand won, while employment cost was 3,350 thousand won. The total output of the smart farm was 33,760 cut flowers, shipped to the domestic market, and sold at 451 won per flower, resulting in a total income of 15,226 thousand won, and a net profit of 5,768 thousand won. The reason why the production volume was less than that of the conventional farm was that the conventional farm planted 180 plants per $3.3 \mathrm{~m}^{2}$, and the smart farm planted 150 plants; and the actual harvest rate was $65.5 \%$ for the conventional farm and $75.0 \%$ for the smart farm, which means it was 9.5\% higher for the smart farm. In addition, net profit per $1,000 \mathrm{~m}^{2}$ was 2,298 thousand won more for the smart farm than the conventional farm. It was found that the smart farm was controlled and managed as an environment suitable for the growth of 'Jinba', and the quality of cut flowers was improved, resulting in a $38 \%$ increase in selling prices as well as production compared to the conventional farm, and a higher net income.

Choi and Lim (2018) analyzed the management performance of strawberry farms that introduced smart farming techniques; the operating cost increased by $2 \%$, but the

Table 6. Management Performance of conventional and smart farm in Chrysanthemum morifolium 'Jinba'.

\begin{tabular}{|c|c|c|c|c|}
\hline \multicolumn{3}{|c|}{ Item } & Conventional farm & Smart farm \\
\hline \multirow{10}{*}{ Expenditure } & & & \multicolumn{2}{|c|}{ (Thousand won $/ 1000 \mathrm{~m}^{2}$ ) } \\
\hline & \multicolumn{2}{|c|}{ Installation cost of smart facility } & 0 & 0 \\
\hline & \multirow{7}{*}{ Input factor } & Seedling cost & 1,414 & 1,350 \\
\hline & & Fertilizer cost & 317 & 500 \\
\hline & & Pesticides cost & 423 & 520 \\
\hline & & Fuel and electricity cost & 3,010 & 3,000 \\
\hline & & Materials cost & 242 & 238 \\
\hline & & Repairing cost & 0 & 0 \\
\hline & & Employment labor cost & 2,687 & 3,850 \\
\hline & \multicolumn{2}{|l|}{ Sum } & 8,093 & 9,458 \\
\hline \multicolumn{3}{|l|}{ Income } & $11,563^{Z}$ & $15,226^{\mathrm{y}}$ \\
\hline \multicolumn{3}{|l|}{ Net income } & 3,470 & 5,768 \\
\hline
\end{tabular}

${ }^{\mathrm{Z}}$ Yield $=35,360$ cut flowers, sales price $=327$ won $/$ flower

${ }^{\mathrm{y}}$ Yield $=33,760$ cut flowers, sales price $=451$ won/flower 
production increased by $2 \%$ through precise growth management, and sales price was increased by $5.2 \%$ due to improvements in quality, resulting in an increase in total income of $8.4 \%$. Tomato production averaged $28.6 \mathrm{~kg}$ per $3.3 \mathrm{~m}^{2}$ in general farms, but was $47.2 \mathrm{~kg}$ for the first-generation simple smart farms, and $84.8 \mathrm{~kg}$ for the second-generation intelligent smart farms, indicating that productivity improved as the smart farm type evolved from the first generation to the second generation (Lee and Seol 2019). According to Kim and Han (2017), smart farms can control unpredictable environmental variables better than conventional farms, enabling year-round production without environmental constraints, as well as improving productivity and quality. Therefore, if $1^{\text {st }}$ or $2^{\text {nd }}$ generation smart farm facilities are introduced and distributed to farms in the cultivation of 'Jinba', it is expected that the farms can be controlled and managed as an environment suitable for growing cut flowers, thereby improving year-round production, quality and productivity to increase the profits of farms.

\section{Conclusion}

A comparative analysis was performed of conventional and smart farms that cultivate Chrysanthemum morifolium 'Jinba' that considered facility status, cultivation environment, cut flower growth and management performance. The conventional and smart farms were located in Muan-gun, Jeollanam-do; the conventional farm cultivated cut flowers in soil in plastic greenhouses, while the smart farm raised those in nutrient solutions at plastic greenhouses. The conventional farm did not have sensors for environmental measurements such as light and temperature, or $\mathrm{pH}$ and EC sensors for fertigation, and all systems such as roof and side window, and thermal screen and shading curtains were operated manually. The smart farm was equipped with sensors for measuring solar radiation, temperature, humidity, $\mathrm{CO}_{2}$, wind speed, rainfall, nutrient solution $\mathrm{pH}$ and EC, and was controlled automatically. The average daytime and nighttime temperatures in the facilities were managed similarly by both farms, but during floral differentiation, the nighttime temperatures were as low as $17.7{ }^{\circ} \mathrm{C}$ in the conventional farm, resulting in delayed floral differentiation, which meant that the cut flowers were harvested 35 days later than the smart farm. It is found that lowering the temperature at night in this way consumes less heating costs, but it causes uneven floral differentiation and delays the harvesting period, which will be a loss in terms of management performance. In addition, the conventional farm maintained unnecessarily high soil moisture and EC in the early stages of growth, and relatively low soil moisture and EC in the period when a lot of moisture and nutrients were required after floral differentiation, so the growth of cut flowers was predicted to be poor. When comparing the quality of the actual cut flowers, it was found that the growth of cut flowers such as length, number of leaves, width, and weight was worse in the conventional farm than in the smart farm.

As described above, there was a difference in the production and quality of cut flowers according to the management level of the cultivation environment between the conventional and smart farms. In terms of management performance, the production and sales prices per $1,000 \mathrm{~m}^{2}$ of the smart farm were $10 \%$ and $38 \%$ higher than those of the conventional farm, respectively. In addition, net profit was 3,470 thousand won for the conventional farm and 5,768 thousand won for the smart farm, meaning that it was $66 \%$ higher for the smart farm.

The smart farm in this study is a first-generation smart greenhouse and has been distributed for the purpose of improving the convenience of farms through remote management. The second-generation smart farm is aimed at improving productivity by developing a growth model for each crop; optimizing growth management through diagnosis and prediction of the growth status of crops according to changes in environmental factors; and automatically measuring and analyzing the growth status and biometric information of plants to derive precise production management conditions (Yoon et al., 2017). Therefore, if the first and second generation smart farms were expanded to conventional farms cultivating cut chrysanthemums, it is expected that it would greatly contribute to the improvement of productivity and quality of cut flowers, as well as to convenience and labor savings in agricultural work. 


\section{References}

Choi, D.W. and C.R. Lim. 2018. Statistical analysis of production efficiency on the strawberry farms using smart farming. J. Korean Soc. Qual. Manag. 46(3):707-716. https://doi.org/10.7469/JKSQM.2018.46.3.707

Choi, S.Y., M.J. Kil, Y.S. Kwon, J.A. Jung, and S.K. Park. 2012. Effect of different Light-emitting diode (LED) on growth and flowering in chrysanthemum. Flower Res. J. 20(3):128-133.

Choi, S.Y., J.H. Lee, and A.K. Lee. 2019. Comparison on quality of cut rose and environment in smart farm and greenhouse. Flower Res. J. 27(2):129-134. https://doi.or g/10.11623/frj.2019.27.2.07

Hahn, E.J., J.H. Bae, and Y.B. Lee. 2000. Growth and photosynthetic characteristics of chrysanthemum plantlets as affected by $\mathrm{pH}$ and EC of nutrient solution in microponic culture. J. Korean Soc. Hortic. Sci. 41(1):12-15.

Kim, G.J. and J.D. Huh. 2015. Trends and prospects of smart farm technology. Electron. Telecommun. Trends 30(5):1-10.

Kim, J.T. and J.S. Han. 2017. Agricultural management innovation through the adotion of internet of things: Case of smart farm. J. Digit. Converg. 15(3):65-75. https://doi.org/10.14400/JDC.2017.15.3.65

Kim, K.S., H.K. Shin, H.Y. Jeong, K.W. Kim, E.Y. Kim, and S.K. Jeong. 2000. Rose, chrysanthemum, and carnation. Seoul, Korea: Nongminsinmunsa.

Kim, Y.J., D.S. Seo, J.Y. Park, and Y.G. Park. 2016. Analysis of management status and development direction of smart farm (pp. 11-36). Naju, Korea: Korea Rural Economic Institute.

Lee, J.K. and B.M. Seol. 2019. Intelligent smart farm and study on productivity: Focused on tomato farm households. Asia Pac. J. Bus. Ventur. Entrep. 14(3):185-199.

Pak, H.S., M.K. Won, D.C. Kim, K.S. Son, Y.J. Park, T.S. Kim, J.J. Choi, and J.H. Kim. 2018. Standard-cut chrysanthemum 'Geumhwa' with yellow petals and early flowering ability under high and low-temperature conditions. Flower Res. J. 26(2):77-83. https://doi.org/1 0.11623/frj. 2018. 26.2.06

Rural Development Administration (RDA). 2015. Simplified analysis method for the management performance of agri- cultural management organizations. Jeonju, Korea: Author.

Roh, Y.S. 2013. Effect of fertilization level and irrigation amount on growth and quality in standard chrysanthemum. Doctoral dissertation, Mokpo National University, Muan, Korea.

Roh, Y.S. and Y.K. Yoo. 2010. Effects of cutting condition on rooting and growth of cut flower in plug cutting of Dendranthema grandiflorum 'Shinma'. Flower Res. J. 18(4):244- 250.

Roh, Y.S. and Y.K. Yoo. 2018. Analysis and improvement plan of cultivation and postharvest management status of cut chrysanthemum farms in Korea. Flower Res. J. 26(4):187-194. https://doi.org/10.11623/frj.2018.26.4.03.

Roh, Y.S., I.K. Kim, and Y.K. Yoo. 2017. Correlation between cultivation environment, cropping system, and quality elements of cut flower and in Dendranthema grandiflorum 'Jinba'. J. People Plants Environ. 20(4):329-339. https://doi.org/10.11628/ksppe.2017.20.4.329.

Yeo, U.H., I.B. Lee, K.S. Kwon, T.H. Ha, S.J. Park, R.W. Kim, and S.Y. Lee. 2016. Analysis of research trend and core technologies based on ICT to materialize smartfarm. Prot. Hortic. Plant Fact. 25(1):30-41. https://doi.org /10.12791/KSBEC.2016.25.1.30

Yoo, D.K. and K.W. Kim. 2004. The effect of watering and $\mathrm{pH}$ on growth and flowering response of Dendranthema grandiflorum cv. Shuhonochikara. J. Korean Flower Res. Soc. 12(2):107-112.

Yoo, Y.K. and Y.S. Roh. 2011. Effects of B9 treatment on growth and quality of cut flower in Dendranthema grandiflorum 'Baekma' (Abstr). Hortic. Sci. Technol. 29(SUPPL. I ):160-161

Yoo, Y.K., Y.S. Roh, B.K. Lee, X.F. Kong, S.Y. Choi. 2009. Growth of Dendranthema grandiflorum 'Baekma' by relighting condition in shade culture (Abstr). Hortic. Sci. Technol. 27(SUPPL. II ):122

Yoo, Y.K., H.J. Oh, Y.S. Roh, and I.K. Kim. 2016. Effects of pretreatment of $\mathrm{NaOCl}$, sucrose, and benzyladenine on vase life and quality of cut flower in standard chrysanthemun 'Jinba'. J. Korean Soc. People Plants Environ. 19(6):559-566. https://doi.org/10.11628/ksppe. 2016.19.6.559

Yoon, N.G., J.S. Lee, K.S. Park, and J.Y. Lee. 2017. Korea smart farm policy and technology development status. Rural Resour. 59(2):19-27. 